\title{
bmj.com at 20 years
}

In this editorial (BMJ 2015;350:h2821, doi:10.1136/bmj.h2821) we credited the US National Library of Medicine as solely responsible for digitising the journal's back archive. In fact, the PubMed Central Backissue Scanning Project was very much a joint venture with the Wellcome Trust and JISC, with the Wellcome Trust paying for most of The BMJ's digitisation.

Cite this as: BMJ 2015;350:h2936

๑ BMJ Publishing Group Ltd 2015 